\title{
Secular Trends in Pediatric Overweight and Obesity in Korea
}

\author{
Jae Hyun Kim ${ }^{1, *}$, Jin Soo Moon ${ }^{2}$ \\ ${ }^{1}$ Department of Pediatrics, Seoul National University Bundang Hospital, Seongnam; ${ }^{2}$ Department of Pediatrics, Seoul National University Children's Hospital, Seoul, \\ Korea
}

Over the previous decades, the prevalence of pediatric obesity has been increased in Korea as well as worldwide. Pediatric obesity is associated with comorbidities in childhood and adulthood. We reviewed the prevalence of pediatric obesity using data from the National School Health Examination (NSHE) and the Korea National Health and Nutrition Examination Survey (KNHANES). Obesity was defined as a body mass index (BMI) $\geq 25 \mathrm{~kg} / \mathrm{m}^{2}$; BMI $\geq 95$ th percentile for the corresponding sex and age in the 2007 growth charts for the NSHE; or BMI $\geq 95$ th percentile for the corresponding sex and age in the 2017 growth charts for the KNHANES. There was a slight discrepancy in the prevalence of obesity depending on the data source. The prevalence of obesity increased from $8.7 \%$ in 2007 to $15.0 \%$ in 2017 in the NSHE (in children aged 6-18 years) and from 8.6\% in 2001 to $9.8 \%$ in 2017 in the KNHANES (in children aged 2-18 years). The increase in the prevalence of obesity was higher in boys and high school students. Accurate epidemiologic data analyzed using the new 2017 growth charts are essential in developing strategies for controlling obesity. Efforts to collect more reliable nationally representative data, including longitudinal studies, are warranted.

Key words: Pediatric obesity, Prevalence, Child, Adolescent, Korea

Received December 28, 2019

Reviewed January 21, 2020

Accepted February 13, 2020

${ }^{*}$ Corresponding author

Jae Hyun Kim

(i)

https://orcid.org/0000-0002-0203-7443

Department of Pediatrics, Seoul National University Bundang Hospital, 82 Gumi-ro 173beon-gil, Bundang-gu, Seongnam 13620, Korea Tel: +82-31-787-7287 Fax: +82-31-787-4054 E-mail:pedendo@snubh.org

\section{INTRODUCTION}

The prevalence of pediatric obesity has increased worldwide over several decades. ${ }^{1}$ Pediatric obesity is a public concern because it is associated with comorbidities, such as type 2 diabetes mellitus (T2DM), dyslipidemia, hypertension, non-alcoholic fatty liver disease, obstructive sleep apnea, polycystic ovary syndrome, and psychiatric problems in childhood. ${ }^{2-6}$ Obesity is also linked to increased health-related expenditure. ${ }^{7}$ Furthermore, children who are overweight or obese have a higher risk for obesity and related disorders in adulthood. ${ }^{8-10}$ High body mass index (BMI), including overweight and obesity, makes a significant contribution to disability-adjusted life-years in adults. ${ }^{11}$

An increasing prevalence of pediatric obesity has been reported in many countries. In the United States, the prevalence of obesity and extreme obesity has markedly increased over the recent several decades. ${ }^{12,13}$ The prevalence of obesity and extreme obesity among children aged 2-19 years in the United States increased from $10.0 \%$ and $2.6 \%$ in $1988-1994$ to $17.2 \%$ and $6.0 \%$ in $2013-2014$, respectively. In China, the prevalence of obesity has increased sharply over the last 30 years. ${ }^{14}$ In Korea, several studies on the prevalence of pediatric obesity have been reported..$^{15}$ Oh et al. ${ }^{16}$ reported that the prevalence of obesity in children increased from 5.8\% in 1998 to $9.7 \%$ in 2005 . However, Nam et al. ${ }^{17}$ showed that the prevalence of overweight and obesity among children and adolescents between 2001 and 2014 had plateaued. Prevalence studies on pediatric obesity using the new 2017 growth charts are not available. In this review, we discuss the up-to-date epidemiologic data on overweight and obesity among Korean children and adolescents.

Copyright @ 2020 Korean Society for the Study of Obesity

(a) This is an Open Access article distributed under the terms of the Creative Commons Attribution Non-Commercial License (https://creativecommons.org/licenses/by-nc/4.o/) which permits unrestricted non-commercial use, distribution, and reproduction in any medium, provided the original work is properly cited. 


\section{SECULAR TRENDS OF OVERWEIGHT AND OBESITY}

Nationally representative data from Korean children and adolescents have been collected through the National School Health Examination (NSHE) and the Korea National Health and Nutrition Examination Survey (KNHANES). Both collection tools have strengths and weaknesses. For NSHE, a sufficient number of participants were enrolled every year. However, there were limitations, such as measurement errors and exclusion of children and adolescents not attending school. On the other hand, the use of trained personnel to perform anthropometric measures in KNHANES makes it reliable. However, due to the relatively small numbers of young participants, the prevalence of overweight and obesity might significantly vary by years.

The NSHE aims to generate baseline data related to health issues of students in elementary, middle, and high schools. The students are assessed annually under the supervision of the Ministry of Education. ${ }^{18} \mathrm{~A}$ two-stage, stratified, cluster sampling method was used in the NSHE to select a representative sample of students in Korea. Recently, more than 80,000 students aged 6 to 18 years participated in the NSHE. The NSHE data was analyzed using the 2007 growth charts, which defined overweight as BMI $\geq 85$ th percentile and
$<95$ th percentile for the corresponding sex and age, and obesity was defined as BMI $\geq 95$ th percentile for the corresponding sex and age or BMI $\geq 25 \mathrm{~kg} / \mathrm{m}^{2} .{ }^{19}$ The prevalence of overweight and obesity increased from $15.3 \%$ to $23.7 \%$ over the last 10 years (Table 1 , Fig. 1). The increasing tendency was observed in both boys and girls (Fig. 2). When stratified by sex and schools, boys and high school students showed a more significant increase in the prevalence of overweight and obesity between 2007 and 2017 (Fig. 3). There was an unexpected increase in the prevalence of overweight and obesity between 2008 and 2009, which was attributed to the application of a more appropriate sampling strategy in 2009. New 2017 growth charts were published in 2018, necessitating a reanalysis using the newly released growth charts. ${ }^{20}$ The 2017 growth charts for BMI were adjusted to lower 95th percentile line, because the previous version had a higher BMI percentile values in boys. In addition, the definition of obesity was changed to BMI $\geq 95$ th percentile for the corresponding sex and age in the 2017 growth charts.

The prevalence of overweight and obesity among children and adolescents can be also obtained from the KNHANES data. The KNHANES is a cross-sectional survey that is conducted annually by the Korea Centers for Disease Control and Prevention and the Ministry of Health and Welfare. ${ }^{21}$ It collects nationally representative data from a multi-stage, clustered, probability design. Recently,

Table 1. Prevalence of overweight and obesity in Korean children and adolescents

\begin{tabular}{|c|c|c|c|c|c|c|c|c|c|c|c|c|c|c|}
\hline \multirow{3}{*}{ Year } & \multicolumn{7}{|c|}{ NSHE (6-18yr) } & \multicolumn{7}{|c|}{ KNHANES (2-18 yr) } \\
\hline & \multirow{2}{*}{$\mathrm{n}$} & \multicolumn{3}{|c|}{ Obesity (\%) } & \multicolumn{3}{|c|}{ Overweight (\%) } & \multirow{2}{*}{$\mathrm{n}$} & \multicolumn{3}{|c|}{ Obesity (\%) } & \multicolumn{3}{|c|}{ Overweight $(\%)$} \\
\hline & & Boy & Girl & Total & Boy & Girl & Total & & Boy & Girl & Total & Boy & Girl & Total \\
\hline 2001 & & & & & & & & 2,982 & 9.9 & 7.1 & 8.6 & 10.1 & 8.4 & 9.3 \\
\hline 2005 & & & & & & & & 1,922 & 9.6 & 8.6 & 9.1 & 8.8 & 9.0 & 8.9 \\
\hline 2007 & 112,401 & 10.7 & 6.6 & 8.7 & 5.4 & 7.9 & 6.6 & 1,118 & 11.6 & 8.1 & 10.0 & 10.1 & 9.3 & 9.7 \\
\hline 2008 & 122,289 & 10.4 & 6.3 & 8.4 & 5.4 & 7.8 & 6.6 & 2,325 & 10.9 & 7.9 & 9.5 & 11.5 & 8.9 & 10.3 \\
\hline 2009 & 194,817 & 13.2 & 8.8 & 11.1 & 7.2 & 9.6 & 8.3 & 2,395 & 9.9 & 7.2 & 8.6 & 10.0 & 9.9 & 9.9 \\
\hline 2010 & 188,352 & 13.9 & 9.1 & 11.7 & 6.7 & 9.3 & 7.9 & 1,984 & 12.1 & 8.2 & 10.3 & 9.3 & 8.7 & 9.0 \\
\hline 2011 & 181,350 & 13.7 & 9.4 & 11.6 & 6.8 & 9.5 & 8.1 & 1,716 & 10.7 & 9.5 & 10.1 & 7.9 & 9.5 & 8.6 \\
\hline 2012 & 87,253 & 14.0 & 11.2 & 12.6 & 5.9 & 8.8 & 7.3 & 1,530 & 9.3 & 8.1 & 8.7 & 9.9 & 8.6 & 9.3 \\
\hline 2013 & 84,480 & 14.9 & 10.5 & 12.8 & 6.8 & 10.8 & 8.7 & 1,688 & 9.7 & 7.5 & 8.6 & 11.7 & 7.2 & 9.5 \\
\hline 2014 & 82,581 & 15.1 & 10.5 & 12.9 & 6.6 & 9.8 & 8.1 & 1,390 & 10.6 & 8.0 & 9.4 & 8.6 & 10.1 & 9.3 \\
\hline 2015 & 84,815 & 15.5 & 11.0 & 13.4 & 6.9 & 9.9 & 8.4 & 1,282 & 10.2 & 9.7 & 9.9 & 9.5 & 7.9 & 8.8 \\
\hline 2016 & 82,883 & 17.1 & 11.2 & 14.3 & 7.2 & 9.7 & 8.4 & 1,570 & 10.9 & 9.5 & 10.2 & 8.2 & 7.1 & 7.7 \\
\hline 2017 & 80,460 & 17.7 & 12.0 & 15.0 & 7.3 & 10.2 & 8.7 & 1,441 & 9.6 & 10.3 & 9.8 & 8.5 & 9.2 & 8.8 \\
\hline
\end{tabular}

Diagnostic criteria for overweight and obesity were based on the 2007 growth charts ${ }^{19}$ for the NSHE and the 2017 growth charts ${ }^{20}$ for the KNHANES. NSHE, National School Health Examination; KNHANES, Korea National Health and Nutrition Examination Survey. 


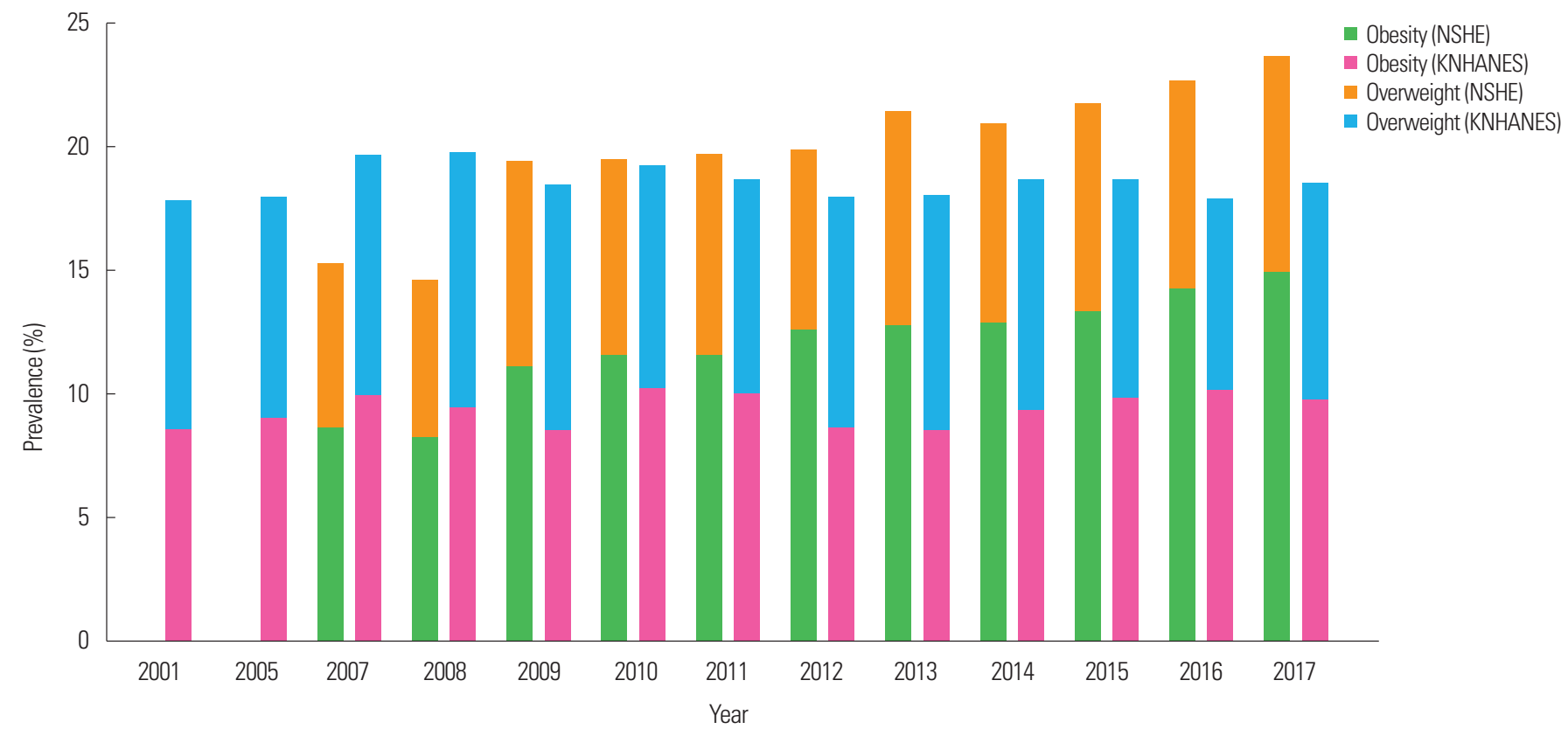

Figure 1. Prevalence of overweight and obesity among Korean children and adolescents. NSHE: children aged 6-18 years, KNHANES: children aged 2-18 years. NSHE, National School Health Examination; KNHANES, Korea National Health and Nutrition Examination Survey.

A

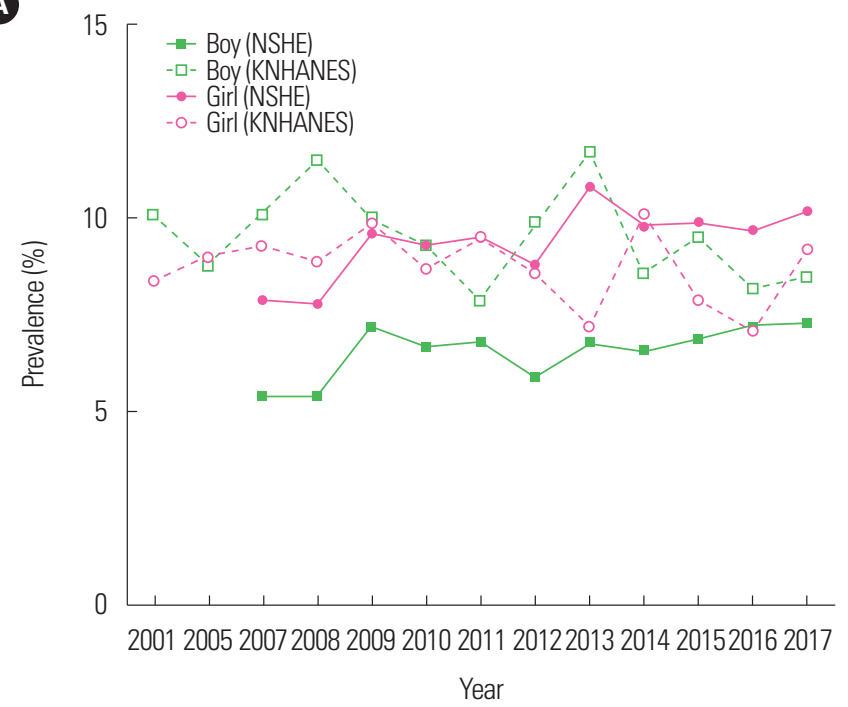

B

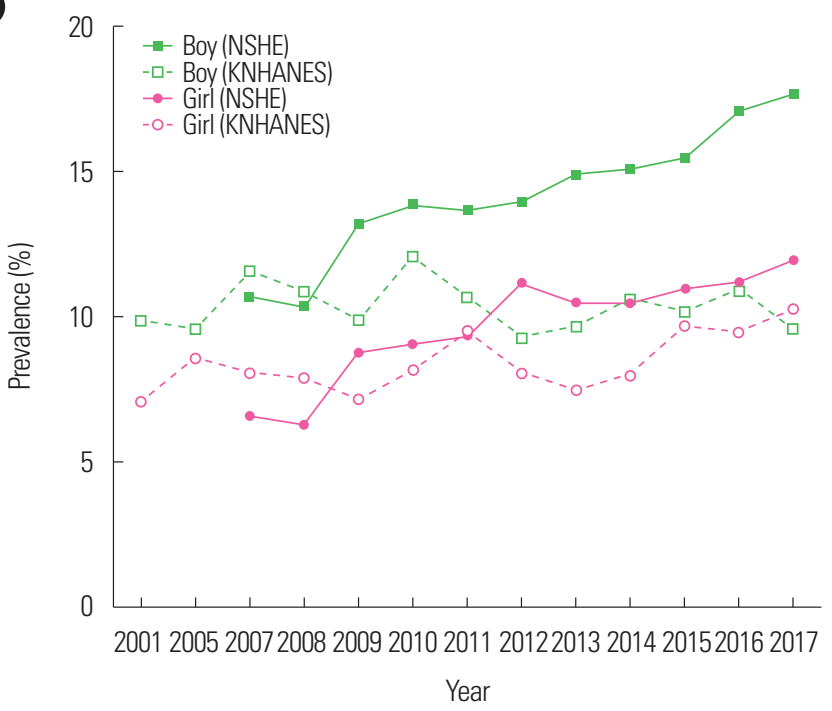

Figure 2. Prevalence of overweight (A) and obesity (B) by sex and year among Korean children and adolescents. NSHE: children aged 6-18 years, KNHANES: children aged 2-18 years. NSHE, National School Health Examination; KNHANES, Korea National Health and Nutrition Examination Survey.

data on overweight and obesity based on the 2017 growth charts was provided. ${ }^{20,22}$ The prevalence of overweight and obesity among children and adolescents aged 2 to 18 years in the KNHANES slightly increased from $17.9 \%$ in 2001 to $18.6 \%$ in 2017 (Table 1, Fig. 1). In boys, the prevalence of obesity was unchanged, although overweight slightly decreased. In girls, the prevalence of both over- weight and obesity increased (Fig. 2). Interestingly, the prevalence of extreme obesity, which was BMI $\geq 120 \%$ of the 95 th percentile, significantly increased from $1.2 \%$ to $2.1 \%$ between 2001 and 2013 $2014(P=0.010) \cdot{ }^{17}$

In Korea, the prevalence of obesity has increased over time. However, the prevalence differs based on the data source and 


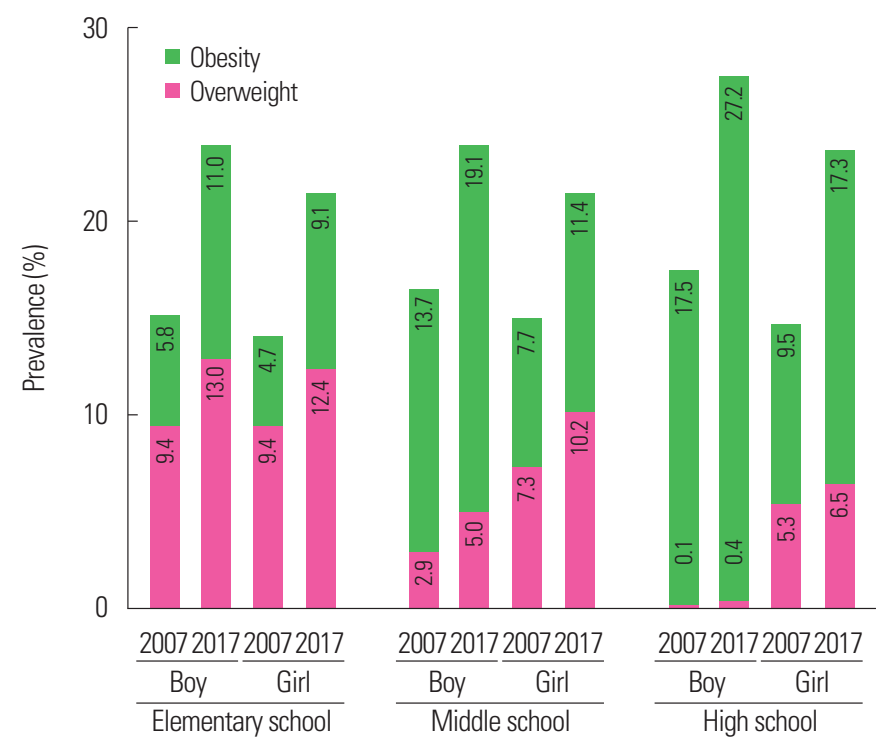

Figure 3. Secular changes in the prevalence of overweight and obesity from the National School Health Examination between 2007 and 2017 by sex and schools.

growth chart references for BMI. The collection of nationally representative data and the application of new growth charts are warranted for the generation of more accurate epidemiological data.

\section{CHARACTERISTICS OF OBESITY IN} KOREAN CHILDREN AND ADOLESCENTS

A recent report from the NSHE and the Korean Youth Health Risk Behavior On-line Survey revealed increased consumption of junk food, frequent skipping of breakfast among middle and high school students, increased sedentary time, and decreased consumption of vegetables over the last 5 years. ${ }^{23}$ According to the KNHANES, total caloric intake and fat intake increased between 2007 and 2015 in children and adolescents. ${ }^{24}$ Approximately $10 \%$ of middle and high school students performed vigorous physical activity for more than 30 minutes 5 days per week, and almost half of high school students slept less than 6 hours per day. According to the KNHANES, the daily time spent in moderate-to-vigorous physical activity has not changed between 2007 and 2015 among those aged 10-18 years. ${ }^{24}$ Low socioeconomic status was associated with obesity in children and adolescents using the KNHANES data. ${ }^{25}$ These are well-known risk factors for developing overweight and obesity in children and adolescents. ${ }^{26-29}$ Interestingly, these behavioral characteristics were more common among high school students, which is in line with the rapidly increased prevalence of obesity in the same population group.

\section{OBESITY-RELATED COMORBIDITIES}

Obesity is associated with dyslipidemia, hypertension, non-alcoholic fatty liver disease, T2DM, and metabolic syndrome. Many studies link pediatric obesity and these diseases in the Korean population. Lim et al. ${ }^{30}$ reported that obese children and adolescents had higher rates of metabolic syndrome, and higher levels of blood pressure, fasting plasma glucose, triglycerides, and low-density lipoprotein cholesterol and they had lower high-density lipoprotein cholesterol than normal-weight counterparts. The prevalence of metabolic syndrome in Korean children and adolescents increased from $4.0 \%$ in 1998 to $7.8 \%$ in 2007 , in conjunction with an increased prevalence of obesity over this time period. ${ }^{31} \mathrm{Seo}$ and $\mathrm{Kim}^{32}$ showed that the BMI z-score was a reliable marker for detecting metabolic syndrome. In another study, children and adolescents with obesity had elevated levels of glycated hemoglobin. ${ }^{33}$ Elevated alanine aminotransferase, a marker for non-alcoholic fatty liver disease, was associated with obesity. ${ }^{34}$ Children and adolescents with obesity had a higher prevalence of elevated blood pressure and hypertension. ${ }^{24}$ However, most studies were cross-sectional and used the KNHANES data. Longitudinal follow-up cohort studies are scarce in Korea.

\section{CONCLUSION}

Pediatric obesity is associated with many comorbidities in childhood and adulthood. In Korea, the prevalence of obesity has increased over time, although there is a slight discrepancy based on data source and the reference on BMI. Accurate epidemiologic data analyzed using the new 2017 growth charts are essential in developing strategies for controlling obesity. Efforts to collect more reliable nationally representative data, including longitudinal studies, are warranted.

\section{CONFLICTS OF INTEREST}

The authors declare no conflict of interest. 


\section{AUTHOR CONTRIBUTIONS}

Study concept and design: JHK; acquisition of data: all authors; analysis and interpretation of data: JHK; drafting of the manuscript: JHK; critical revision of the manuscript: all authors; statistical analysis: JHK; administrative, technical, or material support: all authors; and study supervision: JHK.

\section{REFERENCES}

1. NCD Risk Factor Collaboration (NCD-RisC). Worldwide trends in body-mass index, underweight, overweight, and obesity from 1975 to 2016: a pooled analysis of 2416 populationbased measurement studies in 128.9 million children, adolescents, and adults. Lancet 2017;390:2627-42.

2. Styne DM, Arslanian SA, Connor EL, Farooqi IS, Murad MH, Silverstein JH, et al. Pediatric obesity-assessment, treatment, and prevention: an endocrine society clinical practice guideline. J Clin Endocrinol Metab 2017;102:709-57.

3. Abbasi A, Juszczyk D, van Jaarsveld CH, Gulliford MC. Body mass index and incident type 1 and type 2 diabetes in children and young adults: a retrospective cohort study. J Endocr Soc 2017;1:524-37.

4. Wühl E. Hypertension in childhood obesity. Acta Paediatr 2019;108:37-43.

5. Vos MB, Abrams SH, Barlow SE, Caprio S, Daniels SR, Kohli $\mathrm{R}$, et al. NASPGHAN clinical practice guideline for the diagnosis and treatment of nonalcoholic fatty liver disease in children: recommendations from the expert committee on NAFLD (ECON) and the north American society of pediatric gastroenterology, hepatology and nutrition (NASPGHAN). J Pediatr Gastroenterol Nutr 2017;64:319-34.

6. Turer CB, Brady TM, de Ferranti SD. Obesity, hypertension, and dyslipidemia in childhood are key modifiable antecedents of adult cardiovascular disease: a call to action. Circulation 2018;137:1256-9.

7. Trasande L, Chatterjee S. The impact of obesity on health service utilization and costs in childhood. Obesity (Silver Spring) 2009; 17:1749-54.

8. Llewellyn A, Simmonds M, Owen CG, Woolacott N. Child- hood obesity as a predictor of morbidity in adulthood: a systematic review and meta-analysis. Obes Rev 2016;17:56-67.

9. Juonala M, Magnussen CG, Berenson GS, Venn A, Burns TL, Sabin MA, et al. Childhood adiposity, adult adiposity, and cardiovascular risk factors. N Engl J Med 2011;365:1876-85.

10. Flegal KM, Kit BK, Orpana H, Graubard BI. Association of all-cause mortality with overweight and obesity using standard body mass index categories: a systematic review and meta-analysis. JAMA 2013;309:71-82.

11. GBD 2017 Risk Factor Collaborators. Global, regional, and national comparative risk assessment of 84 behavioural, environmental and occupational, and metabolic risks or clusters of risks for 195 countries and territories, 1990-2017: a systematic analysis for the Global Burden of Disease Study 2017. Lancet 2018;392:1923-94.

12. Skinner AC, Ravanbakht SN, Skelton JA, Perrin EM, Armstrong SC. Prevalence of obesity and severe obesity in US children, 1999-2016. Pediatrics 2018;141:e20173459.

13. Ogden CL, Carroll MD, Lawman HG, Fryar CD, Kruszon-Moran D, Kit BK, et al. Trends in obesity prevalence among children and adolescents in the United States, 1988-1994 through 2013-2014. JAMA 2016;315:2292-9.

14.Zhang N, Ma G. Childhood obesity in China: trends, risk factors, policies and actions. Glob Health J 2018;2:1-13.

15. Moon JS. Secular trends of body sizes in Korean children and adolescents: from 1965 to 2010. Korean J Pediatr 2011;54: 436-42.

16. Oh K, Jang MJ, Lee NY, Moon JS, Lee CG, Yoo MH, et al. Prevalence and trends in obesity among Korean children and adolescents in 1997 and 2005. Korean J Pediatr 2008;51:950-5.

17. Nam HK, Kim HR, Rhie YJ, Lee KH. Trends in the prevalence of extreme obesity among Korean children and adolescents from 2001 to 2014. J Pediatr Endocrinol Metab 2017;30:517-23.

18. Student Health Information Center, Ministry of Education. Student Health Information Center Website [Internet]. Cheongju: Student Health Information Center, Ministry of Education; 2020 [cited 2020 Feb 13]. Available from: http://www. schoolhealth.kr/index.do

19. Moon JS, Lee SY, Nam CM, Choi JM, Choe BK, Seo JW, et al. 2007 Korean National Growth Charts: review of develop- 
mental process and an outlook. Korean J Pediatr 2008;51:1-25. 20. Kim JH, Yun S, Hwang SS, Shim JO, Chae HW, Lee YJ, et al. The 2017 Korean National Growth Charts for children and adolescents: development, improvement, and prospects. Korean J Pediatr 2018;61:135-49.

21. Kweon S, Kim Y, Jang MJ, Kim Y, Kim K, Choi S, et al. Data resource profile: the Korea National Health and Nutrition Examination Survey (KNHANES). Int J Epidemiol 2014;43: 69-77.

22. Korea Centers for Disease Control and Prevention. Korea National Health and Nutrition Examination Survey II-VI. Cheongju: Korea Centers for Disease Control and Prevention; 20012017.

23. Oh YM, Cho AR, Lee DH. Obesity fact sheet 2013-2017. Seoul: Korea Health Promotion Institute; 2018.

24. Cho H, Kim JH. Secular trends in hypertension and elevated blood pressure among Korean children and adolescents in the Korea National Health and Nutrition Examination Survey 20072015. J Clin Hypertens (Greenwich) 2020 Mar 16 [Epub]. https://doi.org/10.1111/jch.13842

25. Lee HJ, Kim SH, Choi SH, Lee JS. The Association between socioeconomic status and obesity in Korean children: an analysis of the fifth Korea National Health and Nutrition Examination Survey (2010-2012). Pediatr Gastroenterol Hepatol Nutr 2017;20:186-93.

26. Zhao Y, Wang L, Xue H, Wang H, Wang Y. Fast food consumption and its associations with obesity and hypertension among children: results from the baseline data of the Childhood Obesity Study in China Mega-cities. BMC Public Health 2017;17: 933.

27. Monzani A, Ricotti R, Caputo M, Solito A, Archero F, Bellone $\mathrm{S}$, et al. A systematic review of the association of skipping break- fast with weight and cardiometabolic risk factors in children and adolescents. what should we better investigate in the future? Nutrients 2019;11:387.

28. Barnett TA, Kelly AS, Young DR, Perry CK, Pratt CA, Edwards NM, et al. Sedentary behaviors in today's youth: approaches to the prevention and management of childhood obesity: a scientific statement from the American heart association. Circulation 2018;138:e142-59.

29. Felső R, Lohner S, Hollódy K, Erhardt É, Molnár D. Relationship between sleep duration and childhood obesity: systematic review including the potential underlying mechanisms. Nutr Metab Cardiovasc Dis 2017;27:751-61.

30. Lim H, Xue H, Wang Y. Association between obesity and metabolic co-morbidities among children and adolescents in South Korea based on national data. BMC Public Health 2014;14: 279.

31.Lim S, Jang HC, Park KS, Cho SI, Lee MG, Joung H, et al. Changes in metabolic syndrome in American and Korean youth, 1997-2008. Pediatrics 2013;131:e214-22.

32. Seo JY, Kim JH. Validation of surrogate markers for metabolic syndrome and cardiometabolic risk factor clustering in children and adolescents: a nationwide population-based study. PLoS One 2017;12:e0186050.

33. Seo JY, Hwang SS, Kim JH, Lee YA, Lee SY, Shin CH, et al. Distribution of glycated haemoglobin and its determinants in Korean youth and young adults: a nationwide population-based study. Sci Rep 2018;8:1962.

34. Park HK, Hwang JS, Moon JS, Lee JA, Kim DH, Lim JS. Healthy range of serum alanine aminotransferase and its predictive power for cardiovascular risk in children and adolescents. J Pediatr Gastroenterol Nutr 2013;56:686-91. 